\title{
Does longer disease-free interval affect the complete remission in metastatic breast cancer?
}

\author{
Kadri Altundag ${ }^{1}$
}

Received: 24 January 2017/ Accepted: 10 February 2017/Published online: 16 February 2017

(C) The Japanese Breast Cancer Society 2017

To the Editor,

I want to congratulate Galli et al. by for their article [1] in which they analyzed the characteristics and outcome of metastatic breast cancer (MBC) patients achieving complete response (CR). They reported that durable CRs can occur after systemic therapy alone or after combined systemic and local treatments. In their study, the authors did not evaluate disease-free interval (DFI) as a factor that may affect CR in MBC. Longer DFI is a well-known positive prognostic factor and characteristic of more indolent underlying disease biology. In one study, the HR+/HER2and HER2+ subgroups with relapsed MBC and DFI more than 5 years experienced similar median overall survival to those with de novo MBC [2]. Therefore, MBC patients with longer DFI are expected to show higher CR.
Compliance with ethical standards

Conflict of interest I have no conflict of interest to declare.

\section{References}

1. Galli G, Tessari A, Porcu L, Bregni G, Paolini B, Carcangiu ML, et al. Complete remission in metastatic breast cancer: expecting the unexpected-results of a cross-sectional study. Breast Cancer. 2017. doi:10.1007/s12282-017-0751-6.

2. den Brok WD, Speers CH, Gondara L, Baxter E, Tyldesley SK, Lohrisch CA. Survival with metastatic breast cancer based on initial presentation, de novo versus relapsed. Breast Cancer Res Treat. 2017;161(3):549-56.
This comment refers to the article available at doi:10.1007/s12282017-0751-6.

\section{Kadri Altundag}

altundag66@yahoo.com

1 MKA Breast Cancer Clinic, Tepe Prime, Cankaya, 06800 Ankara, Turkey 